\title{
Chemical synthesis of dolichyl phosphates, their analogues and derivatives and application of these compounds in biochemical assays ${ }^{\star}$
}

\author{
Leonid L. Danilov and Tatyana N. Druzhinina ${ }^{凶}$ \\ N.K. Kochetkov Laboratory of Carbohydrate Chemistry, N.D. Zelinsky Institute of Organic Chemistry, \\ Russian Academy of Sciences, Moscow, Russia
}

Received: 11 July, 2007; revised: 03 December, 2007; accepted: 07 December, 2007 available on-line: 13 December, 2007

\begin{abstract}
Several methods for simple and efficient chemical synthesis of dolichyl phosphates and their analogues and derivatives are briefly summarized with a special emphasis on chemical modification of phosphoryl group and preparation of dolichyl phosphates labelled at the $\omega$-end and at the $\gamma$-isoprene unit of the isoprene chain by fluorescent groups, 2-aminopyridine and 1-aminonaphtalene residues. Additionally, data on biochemical assays with application of the compounds mentioned above are presented.
\end{abstract}

Keywords: dolichyl phosphates, fluorescent derivatives of Dol-P, Dol-P-Man synthase, FRET methodology

\section{INTRODUCTION}

Long chain isoprenoid alcohols (polyprenols and dolichols) are common constituents of all living cells, but only traces of these compounds have been detected as phosphorylated derivatives. In prokaryotic cells $\alpha$-unsaturated $\mathrm{C}_{55}$ (undecaprenyl) phosphates are widely distributed, whereas $\mathrm{C}_{85}-\mathrm{C}_{105}-2,3-$ dihydropolyprenols (dolichols) with a saturated $\alpha$ isoprene unit and their phosphorylated derivatives are typical for eukaryotes (Rip et al., 1985; Chojnacki \& Dallner, 1988; Schenk et al., 2001).

Polyprenyl and dolichyl phosphates are often called "coenzymes of glycosylation". Biosynthetic cycles for peptidoglycan, capsule polysaccharides (Severin \& Tomasz, 2000; Kamerling, 2000), LPS, teichoic acids biosynthesis and other cell surface glycoconjugates in microorganisms (Roger et al., 1980), as well as the multistep process of protein glycosylation in plants and animals (Kornfeld \& Kornfeld, 1985; Cumming, 1992), and GPI anchor biosynthesis
(Smith et al., 1977) all comprise polyprenyl or dolichyl phosphates and polyprenyl (dolichyl) monoand diphosphate sugars (Schutzbach, 1997).

To study any of the biochemical steps of the biosynthetic cycles mentioned above in vitro it is necessary to have phosphates of polyprenols and dolichyl phosphates. It is worth to notice that living cells are a good source of polyprenols or dolichols whereas concentrations of their phosphates are extremely low and these labile compounds (especially polyprenol derivatives) usually decompose during isolation and purification procedures.

The chemical synthesis of polyprenyl phosphates poses problems different from those encountered with derivatives of dolichols (2,3-dihydropolyprenols).

The aim of this paper is to summarize briefly several methods for simple, reproducible and efficient chemical synthesis of dolichyl phosphates and their analogues and derivatives with a special emphasis on chemical modification of phosphoryl

\footnotetext{
`This paper is dedicated to Professor Tadeusz Chojnacki from the Institute of Biochemistry and Biophysics, Polish Academy of Sciences in Warsaw on the occasion of the 50th anniversary of his scientific activity and 75th birthday.

${ }^{\square}$ Corresponding author: Tatyana N. Druzhinina, N.K. Kochetkov Laboratory of Carbohydrate Chemistry, N.D. Zelinsky Institute of Organic Chemistry, Russian Academy of Sciences, Leninsky prosp. 47, 119991, GSP-1 Moscow, Russia; tel.: (74) 95137 7570; fax: (74) 95137 6148; e-mail: druzh@ioc.ac.ru

Abbreviations: Pre, polyprenyl; Dol, dolichyl; Pre-P, polyprenyl phosphate; Dol-P, dolichyl phosphate; Cit, citronellol; Cit-P, citronellyl phosphate; FRET, fluorescence resonance energy transfer.
} 
group and preparation of dolichyl phosphates labelled at the $\omega$-end and at the $\gamma$-isoprene unit of isoprene chain by fluorescent groups.

Additionally, data on biochemical assays with application of the compounds mentioned above are presented. The main results of investigation in this field were obtained in the N.D. Zelinsky Institute of Organic Chemistry RAS.

\section{METHODS FOR PHOSPHORYLATION OF ISOPRENOID ALCOHOLS}

Historically the first method for phophorylation of polyprenols was developed in 1972 (Warren \& Jeanloz, 1972). It was based on the reaction of the alcohol with $o$-phenylene phosphorochloridate and 2,6-lutidine followed by elimination of the protective group including treatment with lead tetraacetate and further alkaline treatment. Purification of the phosphates was difficult due to the presence of coloured side-products formed after oxidative deblocking.

Up to 1981 this method was practically the only method for phosphorylation of polyprenolic alcohols in spite of all its inconveniences and deficiencies.

The first synthesis of dolichyl phosphate was achieved in 1974 via the procedure cited above (Wedgwood et al., 1974). Initially this method was used in our group for preparation of a series of prenyl phosphates with different chain length (3-16 isoprene units) in 35-62\% yields (Kalinchuk et al., 1985) (Scheme 1).

The multistep procedure, the necessity to remove the protecting group and insufficient method of desired product isolation (usually TLC) retarded investigation of the dolichol pathway. Search for alternative methods of chemical phosphorylation of dolichols and polyprenols turned out a vital task.

In 1981 the first really simple and efficient procedure for preparation of high purity dolichyl phosphate via phosphorus oxychloride as the phosphorylating agent in the presence of base (triethylamine) followed by hydrolysis of intermediate dichloride, isolation and purification of the desired product by anion-exchange chromatography was developed (Danilov \& Chojnacki, 1981) (Scheme 2).

Dolichyl phosphates with 11, 18, 19, 20 and 21 isoprene units were obtained in $57-84 \%$ yields (Table 1). The reaction gave good results even when

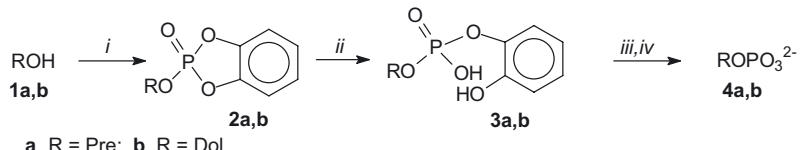

Scheme 1. Reagents: (i) o-phenylene phosphorochloridate, 2,6-lutidine; (ii) $\mathrm{H}_{2} \mathrm{O}$, 2,6-lutidine; (iii) $\mathrm{Pb}(\mathrm{OAc})_{4}$; (iv) $\mathrm{OH}^{-}$.

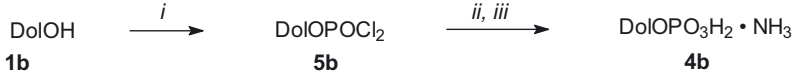

Scheme 2. Reagents: (i) $\mathrm{POCl}_{3}, \mathrm{Et}_{3} \mathrm{~N}$; (ii) $\mathrm{H}_{2} \mathrm{O}, \mathrm{Et}_{3} \mathrm{~N}$; (iii) DEAE-cellulose DE-52(OAc $\left.{ }^{-}\right), \mathrm{NH}_{4} \mathrm{OAc}$.

performed on a very small scale for the preparation of radiolabelled derivatives (yield was calculated based upon radioactivity incorporation). Furthermore citronellyl phosphate (Cit-P, $\omega s-\mathrm{P})$ was prepared through similar way in $67 \%$ yield (Kalinchuk et al., 1985). But this efficient simple method of phosphorylation proved not to be applicable to fully unsaturated polyprenols (no phosphorylated polyprenols were isolated from reaction mixtures).

In recent years, the use of protected phosphochloridates for the synthesis of dolichyl phosphates was practically discontinued after introducing $\mathrm{POCl}_{3}$ as a phosphorylating agent for dolichols.

The propagation of this suitable principle in practice of other researchers was summarized in the following reviews (Danilov \& Shibaev, 1991; Shibaev \& Danilov, 1992; 1997).

Subsequently in 1988a simple and universal method for preparation of monophosphates from alcohols (including dolichols and polyprenols) was developed in our group. Trichloroacetonitrile was proposed initially as a condensing reagent for the reaction of isoprenoid alcohols with bis(triethylammonium) hydrogen phosphate (Cramer \& Boehm, 1959) but this procedure resulted in of mono- and diphosphates of the alcohols. It was revealed in our experiments that the use of tetra$n$-butylammonium dihydrogen phosphate instead of the bis(triethylammonium) salt in the presence of approximately equimolar amount of trichloracetonitrile resulted in preferable monophosphorylation of alcohols and only small amounts of the diphosphates were detected in reaction mixture. After anion-exchange chromatography pure monophosphates of alcohols were isolated in $80-87 \%$ yield (Scheme 3; for more details including reaction conditions and mechanism see Danilov \& Shibaev, 1991; Shibaev \& Danilov, 1997).

Phosphorylation with tetra- $n$-butylammonium dihydrogen phosphate and trichloroacetonitrile was also successfully applied to a series of polyprenols

Table 1. Synthesis of Dol-P via $\mathbf{P O C l}_{3}$

\begin{tabular}{lcc}
\hline Dolichol & $\begin{array}{c}\text { Amount of Dol, } \\
\mathrm{mg}(\mu \mathrm{mol})\end{array}$ & $\begin{array}{c}\text { Yield of Dol-P } \\
(\%)\end{array}$ \\
\hline Dol-11 & $30(39.0)$ & 75.2 \\
Dol-18 & $24(19.2)$ & 68.8 \\
Dol-19 & $35(26.0)$ & 84.0 \\
Dol-20 & $30(21.7)$ & 61.5 \\
Dol-21 & $40(27.6)$ & 69.5 \\
{$\left[{ }^{3} \mathrm{H}\right]$ Dol-19 } & $25 \mu \mathrm{g}(19 \mathrm{nmol})$ & 56.9 \\
\hline
\end{tabular}




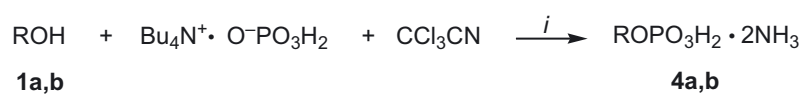

Scheme 3. Reagents: (i) DEAE-cellulose DE-52(OAc $\left.{ }^{-}\right)$, $\mathrm{NH}_{4} \mathrm{OAc}$.

with modified isoprenoid chain in yields of $46-87 \%$ and dolichol $C_{95}$ in $80 \%$ yield (Danilov et al., 1989), retinol, cholesterol, nonacosanol, ethanol, tert-butanol and some other alcohols. In all cases the corresponding monophosphates predominated and were isolated via anion-exchange chromatography in high yields.

At present this seems to be the simplest and most efficient procedure for the preparation of polyprenyl phosphates and related derivatives, first of all for dolichyl phosphates.

\section{SYNTHESIS OF ANALOGUES OF DOLICHYL PHOSPHATE WITH MODIFIED POLAR GROUPS}

Derivatives of dolichyl monophosphate with a modified anionic fragment were synthesized as they could be useful for physicochemical studies and as potential inhibitors of some enzyme reactions. These are double-charged dolichyl thiophosphate (6) (Danilov et al., 1991) and uni-charged dolichyl Hphosphonate (7) (Danilov et al., 1991; Sizova et al., 2003), dolichyl phosphorofluoridate (8) (Sizova et al., 2003) and dolichyl sulfate (9) (Maltsev et al., 2001) (Scheme 4).

Dolichyl thiophosphate (6) was obtained by the reaction of Dol-OH with $\mathrm{PSCl}_{3}$ and Py following saponification and isolation by liquid-liquid extraction as potassium salt.

Dolichyl H-phosphonate (7) was synthesized by reaction of dolichol with triimidazolyl phosphine in a maximum $50 \%$ yield. Recently 2 -chloro- $4 \mathrm{H}-1,3,2-$ benzodioxaphosphorin-4-one (salicyl chlorophosphite) was used as a phosphorylating reagent in the presence of pyridine. Deblocking by treatment with $\mathrm{Py}-\mathrm{H}_{2} \mathrm{O}$ mixture and isolation via anion-exchange chromatography on $\mathrm{DEAE}\left(\mathrm{OAc}^{-}\right)$-cellulose column results in TLC-pure dolichyl H-phosphonate in 93\% yield (Sizova et al., 2003).

A modified analogue of dolichyl phosphate, dolichyl phosphorofluoridate (8) was prepared in a $72 \%$ yield from dolichyl-H-phosphonate, chlorotri-

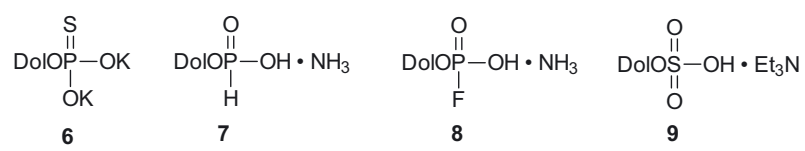

Scheme 4. Anionic derivatives of dolichol. methylsilane, iodine and triethylamine trihydrofluoride. As an example of a dolichyl phosphate derivative lacking the phosphate group dolichyl sulfate (9) was also prepared. The procedure includes reaction of dolichol with $\mathrm{Py} \bullet \mathrm{SO}_{3}$ complex in DMFA followed by isolation the desired product via anion-exchange chromatography $(81 \%)$ or liquid-liquid extraction (73\%).

The possibility of simple and effective preparation of Dol-P stimulated the appearance of a new generation of methods, resulting in the synthesis of more complex dolichyl phospho compounds such as radiolabelled dolichyl $\left[\beta-{ }^{33} \mathrm{P}\right]$ diphosphate via reaction of dolichyl phosphoroimidazolide with trioctylammonium salt of phosphoric acid in 18\% yield (Shabalin et al., 1995). Recently, dolichyl diphosphate was prepared in $64 \%$ yield by reaction of Dol-P with diphenyl phosphorochloridate and interaction of the activated reaction product with tetra- $n$-butylammonium dihydrogen phosphate (Maltsev et al., 1995).

\section{SYNTHESIS OF DOLICHYL PHOSPHOSUGARS}

Also more complex compounds of the dolichol pathway have been synthesized. Thus a new method was developed based on interaction of acetylated glycosyl H-phosphonates with citronellol or dolichol in the presence of pivaloyl chloride followed by oxidation and removal of protecting groups, yielding citronellyl $\beta$-D-galactopyranosyl phosphate $(40 \%)$, dolichyl $\beta$-D-glucopyranosyl phosphate $(62 \%)$ and dolichyl $\beta$-D-galactopyranosyl phosphate (72\%) (Utkina et al., 1995). An original procedure was also applied to the synthesis of dolichyl- $\beta$-D-mannopyranosyl phosphate via interaction of 4,6-di-O-acetyl-2,3di-O-carbonyl- $\alpha$-D-mannopyranosyl bromide with ammonium salt of dolichyl phosphate (52\% yield) (Utkina et al., 1996).

In 1999 a new principle was proposed for the synthesis of dolichyl phosphomonosugars based on interaction of 2,3,4,6-tetra-O-acetyl- $\alpha$-D-glucopyranosyl bromide with salts of citronellyl, dolichyl or citronellyl benzyl phosphate. Citronellyl $\alpha$-D-glucopyranosyl phosphate $(35 \%)$ and dolichyl $\beta$-D-glucopyranosyl phosphate $(65 \%)$ were obtained following this principle (Maltsev et al., 1999).

For dolichyl diphosphate sugars the pioneer method of synthesis proposed in 1978 included interaction of dolichyl diphenyl diphosphate with salt of fully acetylated glycosyl phosphates in the presence of pyridine (Warren \& Jeanloz, 1978). Protecting acetyl groups were eliminated by treatment with sodium methoxide. The results were satisfactory $(40-79 \%)$ only in the cases of derivatives of 2-acetamido-2-deoxy-glycosyl phosphates or containing their oligosaccharides (for a review see Danilov \& 
Shibaev, 1991); derivatives of 1,2-cis-glycosyl phosphates could be obtained only in $6-12 \%$ yield due to considerable decomposition of the peracetylating products obtained in the process of base deacylation probably due to fast splitting of diphosphate linkages and to intramolecular nucleophilic attack of the alkoxide ion appearing on the neighbouring phosphorus atom.

The side reaction discussed above strongly limited application of the diphenyl diphosphate method for the synthesis of dolichyl- and polyprenyl diphosphate sugars. A practical preparation of the compounds became possible after our group developed a phosphoroimidazolide method based on interaction of polyprenyl phosphoroimidazolides with unprotected glycosyl phosphates (Danilov et al., 1981; for a review see Danilov \& Shibaev, 1991). The yields of desired compounds were $22-84 \%$ for polyprenyl diphosphate sugars, containing from monoto tetrasaccharide residues; this method was applicable to this class of compounds containing a dolichol residue (Lee \& Coward, 1992). The synthesis of $\mathrm{P}^{1}$ dolichyl, $\mathrm{P}^{2}$-2-acetamido-2-deoxy- $\alpha$-D-glucopyranosyl diphosphate using dolichyl phosphorodichloridate as activated reagent was performed in a $60 \%$ yield (Imperiali \& Zimmerman, 1990). It proved that at present the phosphoroimidazolide method for the synthesis of lipid diphosphate sugars is the method of choice for dolichyl and polyprenyl glycosyl diphosphates thanks to its efficiency and universality.

Recently, $\mathrm{P}^{1}$-phenoxyundecyl, $\mathrm{P}^{2}$-2-acetamido2-deoxy- $\alpha$-D-glucopyranosyl diphosphate (MontoyaPeleaz et al., 2005) (70\% of final product yield) and $\mathrm{P}^{1}$-phenoxyundecyl, $\quad \mathrm{P}^{2}$-2-acetamido-2-deoxy- $\alpha$-Dgalactopyranosyl diphosphate (60\% yield) (Yi et al., 2006) were synthesized by the phosphoroimidazolide method with minimal alteration of the conjugation conditions. The method was applied also to the synthesis of isoprenoid diphosphate sugar intermediates

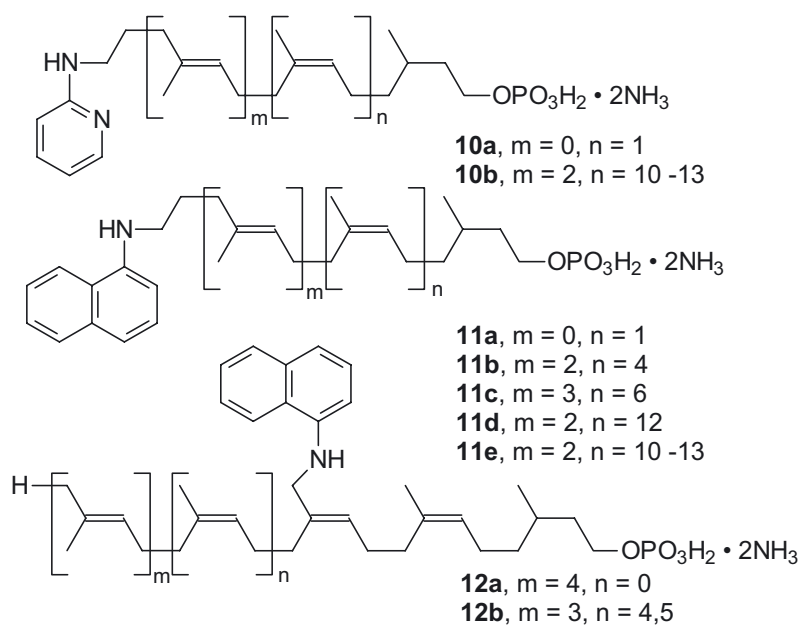

Scheme 5. Dolichyl phosphate derivatives containing fluorescent label at $\omega$ - and $\gamma$-isoprene unit. taking part in the biosynthesis of peptidoglycan (so called Lipid I and Lipid IV). Successful building of $\mathrm{P}-\mathrm{O}-\mathrm{P}$ bridge in the Lipids I and IV and their analogues via phosphoroimidazolide method was described (Ye et al., 2001; Zhang et al., 2007).

\section{SYNTHETIC DERIVATIVES WITH FLUORESCENT LABEL AT ISOPRENOID CHAIN}

This group of fluorescent dolichyl phosphate derivatives is the largest one, comprising compounds with different number of isoprene units and modified at different positions of the isoprenoid chain.

Derivatives of dolichyl phosphate containing 2-aminopyridine or 1-aminonaphtalene fluorophore groups at the $\omega$ - or $\gamma$-isoprene unit of isoprenoid chain were synthesized in our group (Scheme 5) according to the principle of phosphorylation with tetra- $n$-butylammonium dihydrogen phosphate and trichloroacetonitrile (see above, Scheme 3) from corresponding aminoalcohols, specially synthesized (Grigorieva et al., 2000; Shibaev et al., 2000; Xing et al., 2000; Veselovsky et al., 2001; Lamani et al., 2006). The phosphorylation of the aminoalcohols was found to proceed more slowly and to require about double excess of the reagents than for the reaction of nonmodified polyprenols and dolichols, which could be explained by the influence of the amino function in the molecule. The predominant procedure for $\mathrm{pu}-$ rification of the desired phosphates was anion-exchange column chromatography, in some cases liquid-liquid extraction or adsorption chromatography were used. The derivatives showed UV-absorption characteristic for the incorporated chromophores and intensive fluorescence with excitation/emission maxima at $315 / 360 \mathrm{~nm}$ for compounds $\mathbf{1 0 a}, \mathbf{b}$ and 340/410 nm for 11a-e and 12a,b (in $n$-heptane/ 2propanol, 4:1, v/v).Considerable variations in yields (18-93\%) of the compounds could be dependent on structural differences, properties of amino groups in the molecule and the type of isolation and purification procedures.

As a result of these synthetic approaches a new instrument for studies of enzyme reactions was successfully developed. Such collection of dolichyl phosphate derivatives with a fluorescent label in isoprenoid chains should prove to be useful for investigation of intra-and inter-molecular events during enzyme catalysis. Results of such kind of research with recombinant yeast Dol-P-Man synthase are summarized in the final article of this series (see Lamani et al., 2006).

In conclusion of this part we could say that the phosphoroimidazolide method developed in our group for the synthesis of polyprenyl, dolichyl (and 
other lipid) diphosphate sugars in the course of 30 years remains the most general and convenient procedure for preparation of these biologically important derivatives. As it is evident from the data cited above this method has been used successfully up to now and the most recent publication on this subject appeared in the current year.

We have a great pleasure in stressing that at the very beginning of the cascade of syntheses and biochemical investigations there was the idea of Professor Tadeusz Chojnacki to develop a simple and efficient method for dolichol phosphorylation that was first realized in 1981. That synthesis gave the impetus to acceleration and expansion of new chemical and biochemical research.

\section{BIOCHEMICAL RESEARCH WITH SYNTHETIC DERIVATIVES OF DOLICHOLS}

Examples of application of synthetic derivatives of dolichols as lipid acceptors in enzyme cycles could be divided into two groups. In the first group, experiments were performed in the last century with partially purified enzymes, evaluation of substrate characteristics was not always complete and analysis of product structure was preliminary in some experiments.

Research in the second group started in 1999 and final discussion was published in 2006. This series of experiments with homogeneous recombinant enzyme, dolichyl-phosphate-mannose synthase and syntetic Dol-P analogs containing fluorescent probes allowed the intramolecular distances within the protein molecule to be establish as well as the localization of the active and catalytic sites and of the substrates on the enzyme surface, resulting in the construction of a three-dimensional model and proposing a molecular mechanism of catalysis.

One of the first examples of synthetic Dol$P$ assay in an enzyme system was the use of these compounds as monosaccharide acceptor with glycosyltransferases from red clover (Trifolium pratense L.) seedlings (Druzhinina et al., 1981). Incubation of semi-synthetic 2,3-dihydroundecaprenyl phosphate with GDP $\left[{ }^{14} \mathrm{C}\right]$ Man and partially purified preparation of glycosyl transferases resulted in a considerable incorporation of $\left[{ }^{14} \mathrm{C}\right]$ mannose into the fraction of lipid-oligosaccharides. In the case of $\mathrm{C}_{55}$-polyprenyl phosphate the yield of lipid- $\left[{ }^{14} \mathrm{C}\right]$ oligosaccharides was much lover. This result demonstrates that for enzymes from all types of eukaryotic cells, including plants, derivatives of the Dol series but not prenols with fully unsaturated chain are preferable. Stimulation of the biosynthesis of $\mathrm{Dol}_{11}-\mathrm{P}$ and $\mathrm{Dol}_{21}-\mathrm{P}$-oligosaccharide derivatives was slightly higher in the presence of exogenic dolichyl phosphates with long- er isoprenoid chain. For structural analysis of lipidlinked oligosaccharides TLC, column ion exchange on DE-52 and paper chromatographies as well as gel-filtration were used.

Synthetic phosphates of citronellol and dolichols $C_{55}$ and $C_{105}$ were assayed later with enzymes of O-antigen biosynthesis from Salmonella anatum (Kalinchuk et al., 1985). For phosphorylation of $\mathrm{Dol}_{11} \mathrm{OH}$ and $\mathrm{Dol}_{21} \mathrm{OH}$ the procedure with o-phenylenechlorophosphate was used as described earlier (Vergunova et al., 1977). Citronellyl phosphate was prepared following the procedure of Danilov and Chojnacki (1981).

The acceptor ability of polyprenyl phosphates were tested in consecutive reactions of O-antigen biosynthesis: three steps of repeating unit assembly, and in reaction of polymerization. Phosphates of dolichol series could serve as monosaccharide acceptors in reactions of trisaccharide repeating units assembly only in the case of $\mathrm{Dol}_{11} \mathrm{P}$ with efficiency of $39 \%$; the chain length of the most effective derivative coincides with that of native lipid acceptor (11 isoprene units). Dol-P with shorter or longer isoprenoid chain (phosphates of $\mathrm{Dol}_{21} \mathrm{OH}$ and citronellol) are active only with Gal-P transferase, which initiates the process of repeating unit assembly, catalyzing reaction:

$\mathrm{UDPGal}+\operatorname{Pre}_{\mathrm{n}}-\mathrm{P} \rightarrow \mathrm{Gal}(\alpha) \mathrm{ppPre}_{\mathrm{n}}+\mathrm{UDP}$.

The final step of O-specific polysaccharide biosynthesis is enzyme polymerization of trisaccharide repeating unit connected via PP-bridge with $\operatorname{Dol}_{11}$ (Danilov et al., 1989). Biochemically obtained trisaccharide derivatives of $\mathrm{Dol}_{11} \mathrm{PP}$ manifest their substrate ability up to the reaction of trisaccharide repeating unit polymerization with high efficiency (92\%).

Two synthetic analogues of dolichyl phosphate were tested with glycosyl transferases from mammalian microsomes. Dolichyl H-phosphonate could serve as an acceptor for mannosyl-, glucosyland $\mathrm{N}$-acetylglucosaminyl phosphate from GDP$\left[{ }^{14} \mathrm{C}\right]$ Man, UDP- $\left[{ }^{14} \mathrm{C}\right] \mathrm{Glc}$ and UDP- $\left[{ }^{14} \mathrm{C}\right] \mathrm{GlcNAc}$, respectively. The reaction products were characterized by TCL and additional analysis seems to be desirable. Dolichyl sulfate was not a substrate in the enzyme reactions mentioned and demonstrated weak inhibitory properties (Sizova et al., 1998).

The most impressive results were obtained in a series of biochemical research with homogeneous recombinant enzyme, Dol-P-mannose synthase from Saccharomyces cerevisiae (Lamani et al., 2006). In this research fluorescence energy transfer (FRET) methodology was utilized. FRET analysis allows measurements of distances between specific amino-acid residues in the enzyme and fluorophore groups in 
specially designed substrate analogues. A series of 1-aminonaphthalene-labelled dolichyl phosphates having different distances between the fluorophore and the phosphate group of Dol-P were used in these experiments. The FRET experiments allowed for the measurement of distances between selected residues of the enzyme as well as those between the enzyme and chromophoric synthetic Dol-P substrate analogues, thus revealing localization of the active site and the hydrophobic substrate on the enzyme surface. A three-dimensional model of the enzyme was produced with bound substrates, Dol-P, GDPMan and divalent cations. The data allowed for proposing a molecular mechanism of catalysis as an inverting mechanism of mannosyl residue transfer.

\section{Acknowledgement}

We thank our colleagues, Professor Vladimir V. Veselovsky and Professor Leon V. Backinovsky for help in preparation of this manuscript.

\section{REFERENCES}

Borman A (2007) First glimpses of cell wall-forming enzyme will aid search for new antibiotics. Chem Eng New 85: 9.

Chojnacki T, Dallner G (1988) The biological role of dolichol. Biochem J 251: 1-9.

Cramer F, Boehm W (1959) Syntese von Geranyl- und Farnesylpyrophosphate. Angew Chem 71: 775.

Cumming RD (1992) Synthesis of asparagine-linked oligosaccharides: pathways, genetic and metabolic regulation. In: Glycoconjugates, pp 333-360, Kisalius AEC, eds. Dekker M Inc. New York, Basel, Hong-Kong.

Danilov LL, Chojnacki T (1981) A simple procedure for preparing dolichyl monophosphate. FEBS Lett 31: 310312.

Danilov LL, Maltsev SD, Shibaev VN, Kochetkov NK (1981) Synthesis of polyprenyl pyrophosphate sugars from unprotected mono- and oligosaccharide phosphates. Carbohydr Res 88: 203-211.

Danilov LL, Druzhinina TN, Kalinchuk NA, Maltsev SD, Shibaev VN (1989) Polyprenyl phosphates: synthesis and structure activity relationship for a biosynthetic system of Salmonella anatum O-specific polysaccharide. Chem Phys Lipids 59: 191-203.

Danilov VV, Shibaev VN (1991) Phosphopolyprenols and their glycosyl esters: chemical synthesis and their biochemical application. In Studies in Natural Products Chemistry, Atta-ur-Rahman ed, vol 8, pp 63-114, Elsevier, Amsterdam, Oxford, NewYork, Tokyo.

Danilov LL, Maltsev SD, Shibaev VN (1991) Synthesis of 2,3-dihydropolyprenyl H-phosphonates and thiophosphates. Bioorgan Khim 17: 1292-1299.

Druzhinina TN, Pankrushina AN, Shibaev VN, Likholat TV (1981) Biosynthesis of carbohydrate-containing polymers in plants. 1. Products formed with enzyme preparation from clover seedlings. Characterization of polyprenylphosphosugars. Biokhimiya 46: 1445-1457.

Grigorieva NYa, Pinsker OA, Maltsev SD, Danilov LL, Shibaev VN, Jedrzejas MJ (2000a) Dolichyl phosphate derivatives with a fluorescent label at an internal unit (2000). Mendeleev Commun 3: 92-93.

Grigorieva NYa, Pinsker OA, Maltsev SD, Danilov LL, Shibaev VN, Jedrzejas MJ (2000b) Synthesis of dolichyl phosphates with a fluorescent label in the $\gamma$-isoprene unit of chain. Rus Chem Bul Int Ed 49: 2065-2071.

Imperiali B., Zimmerman JW (1990) Synthesis of dolichyllinked oligosaccharides. Tetrahedron Lett 31: 6485-6490.

Kalinchuk NA, Danilov LL, Druzhinina TN, Shibaev VN, Kochetkov NK (1985) Specificity of enzymes of O-antigen biosynthesis in Salmonella anatum towards polyprenyl derivatives of different chain length and saturation. Bioorgan Khim 11: 219-226.

Kammerling J (2000) Pneumococcal polysaccharides. In Streptococcus pneumoniae Molecular Biology and Mechanisms of Deasease. Tomasz A, ed, pp 95-101, Mary Ann Liebert, Inc. publishers. New York.

Kornfeld R, Kornfeld S (1985) Assembly of asparaginelinked oligosaccharides. Annu Rev Biochem 54: 631-664.

Lamani E, Mewborne RB, Fletcher DS, Maltsev SD, Danilov LL, Veselovsky VV, Lozanova AV, Grigorieva NYa, Pinsker OA, Xing J, Forsee WT, Cheung HC, Shutzbach JS, Shibaev VN, Jedrzejas MJ (2006) Structural studies and mechanism of Saccharomyces cerevisiae dolichyl-phosphate-mannose-synthase: insights into the initial step of synthesis of dolichyl-phosphate-linked oligosaccharide chains in membranes of endoplasmic reticulum. Glycobiology 16: 666-678.

Lee J, Coward JK (1992) Enzyme-catalized glycosylation of peptides using a synthetic lipid disaccharide intermediate. J Org Chem 57: 4126-4130.

Maltsev SD, Trifonov AV, Danilov LL, Shibaev VN (1995) Efficient synthesis of polyprenyl diphosphates. Bioorgan Khim 21: 61-65.

Maltsev SD, Danilov LL, Shibaev VN (1999) Glycosylation of citronellyl and dolichyl phosphates with 2,3,4,6-tetra-O-acetyl- $\alpha$-D-glucopyranosyl bromide. Bioorgan Khim 25: 299-305.

Maltsev SD, Sizova OV, Danilov LL, Shibaev VN (2001) Synthesis of dolichyl and polyprenyl sulfates. Russ J Bioorgan Chem 27: 400-403.

Montoya-Peleaz PJ, Riley WA, Szarek WA, Valvano MA, Shutzbach JS, Brockhausen I (2005) Identification of a UDP-Gal: GlcNAc-R galactosyltransferase activity in Escherichia coli VW 187. Bioorgan Med Chem Lett 15: 1205-1211.

Rip JW, Rupar CA, Ravi K, Carroll KK (1985) Distribution, metabolism and functions of dolichols and polyprenols. Progr Lipid Res 24: 269-309.

Rogers HJ, Perkins HR, Ward JB (1980) Biosynthesis of peptidoglycan. In Microbial Cell Walls and Membranes, pp 239-297, Chapman \& Hall, University Press, Cambridge London-New York. ibid., Biosynthesis of teichoic acids, pp 381-401, Biosynthesis of lipopolysaccharides, pp 407-424.

Schenk B, Fernandez F, Waechter CJ (2001) The ins(ide) and outs(ide) of dolichyl phosphate biosynthesis and recycling in the endoplasmic reticulum. Glycobiology 11: 61R-70R.

Schutzbach JS (1997) The role of the lipid matrix in the biosynthesis of dolichyl-linked oligosaccharides. Glycoconj J 14: 175-182.

Severin A, Tomasz A (2000) The peptidoglycan of S. pneumoniae, In Streptococcus pneumoniae Molecular Biology and Mechanisms of Deasease. Tomasz A, ed, pp 179-195, Mary Ann Liebert, Inc. publishers. New York. .

Shabalin YuA, Naumov AV, Vagabov VM, Kulaev IS, Danilov LL, Shibaev VN (1995) Synthesis of dolichyl 
$\left[\beta-{ }^{33} \mathrm{P}\right]$ pyrophosphate and dolichyl pyrophosphate mannose. Bioorgan Khim 11: 651-654.

Shibaev VN, Danilov LL (1992) New developments in the synthesis of phosphoprenols and their glycosyl esters. Biochem Cell Biol 70: 429-437.

Shibaev VN, Danilov LL (1997) Synthesis of intermediates in the dolichol pathway of protein glycosylation. In Glycopeptides and Related Compounds: Synthesis, Analysis and Application, Large DG, Warren CD eds, pp 427-504, Dekker M Inc., New York, Basel, Hong-Kong.

Shibaev VN, Veselovsky VV, Lozanova AV, Maltsev SD, Danilov LL, Forsee WT, Xing J, Cheung HC, Jedrzejas MJ (2000) Synthesis of dolichyl phosphate derivatives with fluorescent label at the $\omega$-end of the chain, new tools to study protein glycosylation. Bioorg Med Chem Lett 10: 189-192.

Sizova OV, Maltsev SD, ShibaevVN, Jankowski WJ, Chojnacki T (1998) Dolichyl sulfate and H-phosphonate: enzymic reactions with activated sugars. Acta Biochim Polon 45: 1021-1030.

Sizova OV, Maltsev SD, Shibaev VN (2003) A synthesis of dolichyl phosphorofluoridate. Russ J Bioorgan Chem 29: 387-389.

Sizova OV, Maltsev SD, Shibaev VN, Jankovski WJ, Chojnacki T (1988) Dolichyl sulfate and H-phosphonate enzymatic reactions with activated sugars. Acta Biochim Polon 45: 1021-1030.

Smith TK, Milne FC, Sharma DK, Crossman A, Brimacombe S, Ferguson MAJ (1997) Early steps in glycosylphosphatidylinositol biosynthesis in Leishmania major. Biochem J 326: 393-400.

Utkina NS, Maltsev SD, Danilov LL, Shibaev VN (1995) Synthesis of citronellyl and dolichyl glycosyl phosphates, derivatves of $\beta$-D-glucose and $\beta$-D-galactose, by H-phosphonate method. Bioorgan Khim 21: 376-381.

Utkina NS, Maltsev SD, Danilov LL, Shibaev VN (1996) Synthesis of dolichyl $\beta$-D-mannopyranosyl phosphate. Bioorgan Khim 22: 314-315.

Vergunova GI, Glukhoded IS, Danilov LL, Eliseeva GI, Kochetkov NK, Troitsky MF, Usov AI, Shashkov AS, Shibaev VN (1977) The structure of moraprenol and the synthesis of moraprenyl phosphate. Bioorgan Khim 3: 1484-1492.
Veselovsky VV, Lozanova AV, Maltsev SD, Danilov LL, Shibaev VN, Jedrzejas MJ (2001a) Fluorescent-labeled derivatives of dolichyl phosphate. Analogs of dolichyl phosphate with 2-aminopyridine residue at the $\omega$-end of chain. Russ Chem Bull Int Ed 50: 531-536.

Veselovsky VV, Lozanova AV, Maltsev SD, Danilov LL, Shibaev VN, Jedrzejas MJ (2001b) Derivatives of dolichyl phosphate with fluorescent label. Analogs of dolichyl phosphate with different length of isoprene chain containing the (1-naphtyl)amino group in the $\omega$-fragment. Russ Chem Bull Int Ed 50: 2221-2226.

Warren CD, Jeanloz RW (1972) Chemical synthesis of pyrophosphodiesters of carbohydrates and isoprenoid alcohols. Lipid intermediates of bacterial cell wall and antigenic polysaccharide biosynthesis. Biochemistry 11: 2565-2573.

Warren CD, Jeanloz RW (1978) Chemical synthesis of dolichyl phosphate and dolichyl glycosyl phosphates and pyrophosphates of "dolichol intermediates". Methods Enzymol 50: 122-157.

Wedgwood JF, Strominger JL, Warren CD (1974) Transfer of sugar from nucleoside diphosphate sugar compounds to endogenous and synthetic dolichyl phosphate in human lymphocytes. J Biol Chem 249: 63166320.

Xing J, Forsee WT, Lamani E, Maltsev SD, Danilov LL, Shibaev VN, Schutzbach JS, Cheung HC, Jedrzejas MJ (2000) Investigation of the active site of Saccharomyces cerevisiae dolichyl-phosphate-mannose synthase using fluorescent labeled dolichyl-phosphate derivatives. Biochemistry 39: 7886-7894.

Ye X-Y, Lo M-C, Brunner L, Walker D, Kahne D, Walker S (2001) Better substrates for bacterial transglycosylases. J Am Chem Soc 123: 3155-3156.

Yi W, Yao Q, Zhang Y, Motari E, Lin S, Wang PG (2006) The wbuH gene of Escherichia coli O86:H2 encodes an $\alpha-1,3-N$-acetylgalactosaminyl transferase involved in Orepeating unit biosynthesis. Biochem Biophys Res Commun 344: 631-639.

Zhang Y, Fechter EJ, Wang T-S, Barrett D, Walker S, Kahne DE (2007) Synthesis of heptaprenyl-Lipid IV to analyze peptidoglycan glycosyl transferases. I Am Chem Soc 129: 3080-3081. 